\title{
PRODUTIVISMO ACADÊMICO E SUAS REPERCUSSÕES NO DESENVOLVIMENTO PROFISSIONAL DE PROFESSORES UNIVERSITÁRIOS*
}

\author{
Dilmeire Sant'Anna Ramos Vosgerau ${ }^{1}$ \\ Evelyn de Almeida Orlando ${ }^{2}$ \\ Patricia MeYer ${ }^{3}$
}

\begin{abstract}
RESUMO: Entre as distintas dimensōes do trabalho docente, a pesquisa é uma das mais prestigiadas. É a partir dela que universidades e profissionais são avaliados em sua qualidade e produtividade. $\mathrm{O}$ texto analisa quatro documentos da Coordenaçáo de Aperfeiçoamento de Pessoal de Nível Superior (Capes), visando discutir o impacto da lógica do produtivismo acadêmico no desenvolvimento profissional docente a partir da compreensão do professor como intelectual. Embora seja objetivo da Capes a formação de recursos humanos qualificados para a docência em grau superior, as suas estratégias de avaliação, ao privilegiar a quantidade de publicaçóes, provocam consequências não somente com relação à pertinência da produção científica, mas também à manutenção da insuficiente formação didático-pedagógica de professores atuantes na graduaçáo.
\end{abstract}

Palavras-chave: Ensino Superior. Coordenação de Aperfeiçoamento de Pessoal de Nível superior. Trabalho intelectual. Professor universitário. Desenvolvimento profissional.

\section{ACADEMIC PRODUCTIVISM AND ITS REPERCUSSIONS IN THE PROFESSIONAL DEVELOPMENT OF PROFESSORS}

ABSTRACT: Among the different dimensions of teaching, research is one of the most prestigious. It is from this that universities and professionals are evaluated on quality and productivity. The text analyzes four documents of Higher Education Personnel Improvement

\footnotetext{
*Artigo resultante do Projeto de Pesquisa OBSERVA - Observatório de processos de inovaçáo e criatividade nas práticas de ensino e de aprendizagem no ensino superior, que recebeu apoio do Fundo de Pesquisa da Pró-Reitoria de Pós-Graduação da PUCPR.

${ }^{1}$ Pontifícia Universidade Católica do Paraná, Programa de Pós-Graduação em Educação - Curitiba (PR), Brasil. E-mail: dilmeire.vosgerau@pucpr.br

${ }^{2}$ Pontifícia Universidade Católica do Paraná, Programa de Pós-Graduação em Educação - Curitiba (PR), Brasil. E-mail: evelynorlando@gmail.com

${ }^{3}$ Instituto Federal do Paraná. Pontifícia Universidade Católica do Paraná. Professora na área de Comunicação - Curitiba (PR), Brasil. E-mail: patricia.meyer@ifpr.edu.br

DOI: 10.1590/ES0101-73302016163514
} 
Coordination (Capes) in order to discuss the impact of the logic of academic productivism in teacher professional development from the understanding of professor as intellectual. Although the objective of Capes is the formation of qualified human resources for teaching in higher grade, its evaluation strategies, by privileging the amount of publications, cause consequences not only in relevance of the scientific production as in the insufficient maintenance of the pedagogical and didactic formation of teachers working at graduation.

Keywords: Higher education. Higher Education Personnel Improvement Coordination. Intellectual work. College professor. Professional development.

\section{LE PRODUCTIVISME ACADEMIQUE ET SES REPERCUSSIONS DANS LE DEVELOPPEMENT PROFESSIONNEL DES PROFESSEURS UNIVERSITAIRES}

RÉSUMÉ: Parmi les différentes dimensions du travail du professeur, la recherche est une des plus prestigieuses et c'est en relation à sa qualité et sa productivité que les universités et les professionnels sont évalués. Le texte analyse quatre documents de la Coordination d'Amélioration au Personnel de l'enseignement supérieur (Capes) afin de discuter l'impact de la logique du productivisme académique dans le développement professionnel des enseignants en les considérant comme des intellectuels. Même si l'objectif de la Capes est la formation de ressources humaines qualifiées pour l'enseignement en classe supérieure, ses stratégies d'évaluation, tout en privilégiant la quantité de publications, entraînent des conséquences non seulement à ce qui concerne la pertinence de la communauté scientifique, mais aussi l'entretien de la formation didactique et pédagogique insuffisante des enseignants qui travaillent à l'obtention du diplôme de licence.

Mots-clés: Enseignement supérieur. Coordination d'Amélioration au Personnel de l'enseignement supérieur (Capes). Travail intellectuel. Professeur universitaire. Développement professionnel du professeur.

\section{Introdução}

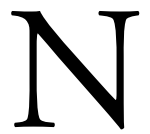

o Brasil, a formação dos professores universitários está, progressivamente, ficando sob responsabilidade dos cursos de pós-graduação stricto sensu, embora se discuta que estes cursos não são suficientes para o desenvolvimento profissional docente (CUNHA, 2014).

A própria Lei no 9.394 (BRASIL, 1996) prescreve esses cursos como espaço de formação do professor universitário ao exigir que um terço do corpo docente das instituiçóes universitárias tenha titulação acadêmica de mestrado ou doutorado (SOARES; CUNHA, 2010). Os programas de pós-graduação em 
Educação, portanto, têm uma importante finalidade ao acolher professores universitários de diferentes áreas e oferecer-lhes a formação para a docência. Contudo, ressalta-se que a pós-graduação stricto sensu concentra-se na formação do pesquisador e, por vezes, silencia-se em relação à formação didático-pedagógica das novas geraçóes de mestres e doutores. Isso implica na naturalização da perspectiva de que, para ensinar nas salas de aulas dentro das universidades, basta o conhecimento específico das disciplinas acadêmicas ou a experiência profissional em determinada área de atuação (CUNHA, 2014) ou, ainda, o fato de que só ensinando é possível aprender a ensinar. Portanto, a formação dos docentes não é prioridade, o que também se evidencia pelo fato de que esse não é um critério de avaliação do desempenho das instituiçôes de ensino superior (ZABALZA, 2004). As avaliaçóes estão voltadas ao número de patentes, pesquisas e publicaçóes ou ao grau de internacionalização, o que é reafirmado pelo Plano Nacional de Pós-Graduação (PNPG) vigente (BRASIL, 2010).

Mesmo nos processos de seleção de professores, a experiência na área de origem, a formação acadêmica e a produção científica se sobrepóem à formação didático-pedagógica do profissional - fato que explicita que o perfil de pesquisador passa a se constituir no vetor da qualidade da educação superior e, portanto, da condição de docente. Nas universidades públicas, a titulação é exigida já no ato de inscrição dos concursos públicos para provimento de cargos de professores (SGUISSARDI; SILVA JÚNIOR, 2009). Consagra-se a ideia de que quem sabe pesquisar, sabe ensinar (CUNHA; ZANCHET; RIBEIRO, 2013).

Para o professor universitário, o conhecimento pedagógico é considerado secundário em relação ao domínio de sua especialidade, e repete-se o autodidatismo questionado desde a constituição das primeiras universidades. Contudo, Soares e Cunha (2010) ressaltam que a docência é complexa e requer múltiplos saberes para seu efetivo exercício. A experiência profissional ou o conhecimento científico são apenas uma parte; para assegurar a aprendizagem do estudante, são exigidas do professor outras competências e atitudes. Isso porque a ausência de saberes pedagógicos limita a açáo docente e impacta em diferentes obstáculos ao processo de ensinar e aprender. O processo de aprendizagem de estudantes universitários implica em uma transposição de dependência para a autonomia, o que pressupóe “engajamento consciente e voluntário". Isso demanda do professor a necessidade de explanar e persuadir, demonstrando a finalidade e a aplicabilidade em se estudar os conteúdos, assim como "negociar as formas para trabalhar esses conteúdos e avaliar a aprendizagem realizada" (SOARES; CUNHA, 2010, p. 27).

Esse prestígio do pesquisador, somado ao baixo estatuto epistemológico do conhecimento pedagógico e a subjetividade da docência, pode justificar a precariedade atual da formação docente na universidade (CUNHA, 2014). É da pesquisa que provém parte significativa do financiamento das universidades; dessa forma, o produto da educaçáo superior se sobrepóe aos processos, fazendo da 
pesquisa o principal componente do reconhecimento docente (CUNHA; ZANCHET; RIBEIRO, 2013). Na prática, há uma escala hierárquica de valorização em relação às atividades-fim da universidade: pesquisa, ensino (pós-graduação e depois graduação) e extensão. Na graduação há maior importância para a iniciação científica do que para a aula ${ }^{1}$ (SGUISSARDI; SILVA JÚNIOR, 2009).

Assim, as próprias políticas de Estado, ao investir na ciência e tecnologia e aferir os resultados por intermédio da Capes e do Conselho Nacional de Desenvolvimento Científico e Tecnológico (CNPq), interferem na identidade das instituições de ensino superior e no trabalho do professor universitário. Sguissardi e Silva Júnior (2009) citam como reflexos dessas políticas a indução de pesquisas aplicadas, aliadas aos interesses produtivos, e o produtivismo acadêmico, o que implica na proliferação de doutores focados na produção de resultados, baseados em pesquisas efêmeras; afinal, eles são valorizados em suas respectivas áreas de atuação por critérios meramente quantitativos. Para o Estado, a pós-graduação é um espaço central onde a pesquisa é desenvolvida com maior consistência. Por isso, Sguissardi e Silva Júnior (2009, p. 61) afirmam que está nela a origem de um "processo de mercantilização da universidade (estatal pública brasileira)". Para os autores, o mesmo fenômeno que superqualifica a pós-graduação, desqualifica a graduação e a prática da docência.

$\mathrm{Na}$ visão de professor e universidade de Anísio Teixeira ${ }^{2}$ (MENDONÇA, 2002), assim como na perspectiva defendida por Sirinelli (1996), parte-se do pressuposto de que os professores universitários são intelectuais, com papel decisivo na produção e na circulação de conhecimento por meio da interlocução nos espaços educativos, da pesquisa e do engajamento em causas sociais.

O Parecer no 977 (BRASIL, 1965) destinou à Capes a atribuição e recursos orçamentários para intervir na qualificação dos professores das universidades brasileiras. A partir de 2007, além de acompanhar e avaliar os cursos de pós-graduação stricto sensu, a Capes passou a fomentar a formaçáo inicial e continuada de professores para a educação básica por meio da Política Nacional de Formação de Profissionais do Magistério da Educação Básica, atribuição consolidada pelo Decreto no 6.755, de 29 de janeiro de 2009 (BRASIL, 2009). Contudo, não há qualquer tipo de indicação de supervisão em relação à formação didático-pedagógica de professor universitário. Mesmo os instrumentos de avaliação do Instituto Nacional de Estudos e Pesquisas Educacionais Anísio Teixeira (Inep) citam apenas, em relação aos professores, titulação, regime de trabalho, experiência profissional na docência, tanto em educação básica como em superior, e produção científica, cultural, artística ou tecnológica.

Se cabe à universidade a formação do indivíduo para o exercício da cidadania, para a excelência profissional e autonomia, sob a perspectiva de que o curso de graduação é apenas uma etapa em seu itinerário de formação que se dará ao longo de toda a sua vida, é imprescindível a compreensão da responsabilidade 
do professor universitário. Entretanto, as lacunas são incontestáveis e não se evidencia o reconhecimento em relaçáo ao trabalho que se estabelece em sala de aula. Em muitas instituiçốes de ensino superior, ainda não há a promoção de programas sistêmicos de formação didático-pedagógica ou são mantidas apenas açôes de atualização pontuais, teóricas e descontinuadas, sem reflexão sobre a prática e sem conexão com as demandas apontadas pelos docentes.

\section{O professor como intelectual}

O projeto de constituição de uma cultura nacional nas décadas de 1920 e 1930 incorpora o debate sobre educação e formação das elites intelectuais. Em paralelo à discussão sobre a necessidade de expansão da escola básica e pública, evidencia-se, pelo movimento dos intelectuais denominados pioneiros ${ }^{3}$, a defesa de criação das universidades dedicadas à formação das elites para "pensar o Brasil" (MENDONÇA, 2002, p. 21). Para Anísio Teixeira, a universidade não poderia se restringir a uma visáo utilitarista de formação profissional ou difusão de conhecimentos. A função da universidade é "formular intelectualmente a experiência humana, sempre renovada" (TEIXEIRA, 2010, p. 33), ser um polo de irradiação cultural e fonte de criaçáo da identidade de um povo. Era papel da universidade combater o autodidatismo - que vinha formando o quadro de intelectuais do país - e o isolamento intelectual (TEIXEIRA, 2010), privilegiando a socialização do saber. A universidade precisava ser capaz de formar os intelectuais do país, mas sua definiçáo de intelectual náo se restringia à elite. Entendia a universidade como espaço democrático e de encontro entre sujeitos que querem aprender, e compreendia o professorado como parte da elite intelectual brasileira.

Teixeira (2010) defendia, ainda, que a escola não poderia admitir o empiricismo por parte do professor, afinal ele é o responsável direto pela transformação na escola. Para o autor, conteúdo e metodologia de ensino são indissociáveis, portanto ele considerava que o professor deveria ter profundo conhecimento da matéria que ensinaria, além de dominar as técnicas e os processos que tornam possível a aprendizagem do aluno. Para o educador, a formação dos professores também era função da universidade. Por isso, combatendo a visão de desprestígio da formação pedagógica, na Universidade do Distrito Federal (UDF), seu projeto de "Universidade de Educação" defendeu que cabia às instituiçôes de ensino superior prover a formação para o magistério em todos os graus de atuação, em uma dimensão profissional e intelectual, tendo em vista a criação de uma cultura pedagógica nacional. Acreditava que teria, como resultado do fortalecimento da educação como campo científico, o desenvolvimento de pesquisas educacionais que pudessem reconstruir a educação.

Com o fim do projeto da UDF, a visão de Teixeira de institucionalizar o estudo científico da educação foi substituída por uma visão corporativa e buro- 
cratizada da atividade educativa, que se evidencia até hoje no desprestígio acerca dos estudos superiores em Educação. "[...] gerou-se uma situação peculiar, já que o campo da educaçáo acabou por se profissionalizar, sem que tenha conseguido institucionalizar-se como área de estudo e pesquisa em nível acadêmico" (MENDONÇA, 2002, p. 42).

Teixeira (2010) defendeu uma visão integrada do ensino e da pesquisa, com a valorização da extensão ou irradiação do saber científico, a partir da universidade, para a sociedade. Até os dias atuais, essa visão democrática é referência para as propostas que visam transpor o isolamento da universidade em relação às problemáticas sociais, assim como integrá-la e engajá-la para o fortalecimento da educação, em uma perspectiva de articulação entre escola básica e universidade. O estudioso também defendeu a necessidade de pensamento divergente como um requisito de liberdade e criatividade para a reflexão acadêmica.

A atuaçáo de forma dialogada, cooperativa e coletiva continua sendo um grande desafio para os professores universitários. A liberdade de cátedra tornou-se sinônimo de trabalho individual e de autonomia, no sentido de que "o professor pode fazer o que quer em sala de aula" (ZABALZA, 2004). Os professores trabalham sozinhos, protegidos pela iniciativa pessoal e pela liberdade acadêmica, confundindo solidáo com autonomia, e temendo o julgamento de seus pares. No entanto, tal isolamento não é benéfico para seu exercício profissional, para a articulação dos conteúdos e integração das disciplinas ou para o desenvolvimento de estratégias pedagógicas institucionais (RUIZ, 2008). A não institucionalização da educação como campo científico e o cenário de desprestígio em relação a essa área do conhecimento ainda têm fortes reflexos. Entre eles, encontra-se o desinteresse pela atuação em sala de aula demonstrado por alguns professores que atuam nas universidades. O trabalho na graduação é definido como um "consumidor de tempo" (SGUISSARDI; SILVA JÚNIOR, 2009, p. 176).

A prioridade está em produzir ciência e participar de eventos científicos, bem como emitir avaliaçôes, pareceres e elaborar artigos, pois essa participação é efetivamente julgada, avaliada e gera reconhecimento. Afinal, "os critérios de avaliação e progressão na carreira docente são essencialmente relacionados à pesquisa" (SOARES; CUNHA, 2010, p. 23), e não ao complexo e invisível trabalho empreendido na docência. A avaliação externa à qual a atividade na pós-graduação está submetida leva a outro reflexo relacionado à intensificação do trabalho docente: a pressãó .

A competitividade está enraizada no funcionamento das instituiçóes de ensino superior. Em relação à pós-graduação, as exigências e os critérios de avaliação da Capes repercutem em um crescente individualismo, resultante da disputa por publicações, bolsas e financiamento. $\mathrm{O}$ reflexo se dá tanto na intensificação e na precarização do trabalho do professor como no enfraquecimento do sentimento de pertença a um coletivo. Acirra-se a pressão entre professores, o que também incide 
nos estudantes de doutorado, mestrado, iniciação científica e graduação (SGUISSARDI; SILVA JÚNIOR, 2009). Aliados, a perspectiva utilitarista da pesquisa e o individualismo levam à fragmentação da identidade do professor como intelectual.

Em ensaio sobre Sartre, Sirinelli (2006, p. 163) explica que a notoriedade do filósofo foi decorrente da produção e da ocupação de espaços de divulgação e circulação de ideias. Além disso, ele enfatiza que, para Sartre, "o papel do intelectual é pensar essa história e tentar, como intelectual engajado, influir sobre ela". Assim, a reputação de Sartre contribuiu para que ele tivesse ampla repercussão e ressonância de suas ideias políticas e seus engajamentos. $\mathrm{O}$ conceito de intelectual não se restringe à produção e circulação do saber, pois engloba "suas tomadas de decisóes públicas" (SIRINELLI, 2006, p. 161). O autor destaca que há uma acepção mais ampla do termo, que define os intelectuais como mediadores e receptores de cultura (escritores, jornalistas, professores e até potenciais intelectuais, como estudantes), e uma mais estreita, que determina que os intelectuais são sujeitos atores na vida das cidades, com atuaçáo legítima para intervir e se colocar a serviço das causas que defendem.

Ribeiro (2006, p. 141), filósofo e Ministro da Educação em 2015, afirma que o intelectual é aquele que dá caráter público ao seu conhecimento, abrindo o ambiente acadêmico - o que não significa apenas palestrar, mas "efetuar todas as mediaçóes, que convertam o que inicialmente seria trabalho arcano, acadêmico, fechado sobre si, voltado apenas ao avanço interno do conhecimento, em algo que passa a ser apropriado socialmente". Ribeiro (2006, p. 146-147) enfatiza, ainda, que o intelectual é "o político do conhecimento" ou "da ciência", que "faz [com] que a ciência se torne cultura". Compreende-se, portanto, o professor universitário como intelectual; e intelectualidade não se trata apenas de produção, circulação e divulgação científica, mas também de atuação política em diferentes espaços, no sentido de estabelecer mediaçóes que tornem possível a apropriaçáo social do conhecimento. A atuação do intelectual compreende a mediação cultural. "O papel do intelectual consiste em articular valores e conhecimentos, ideias e ideais" (RIBEIRO, 2006, p. 142). A sala de aula é, entáo, ambiente de diálogo, de exercício do pensamento contraditório, de estímulo à participação, na mesma medida em que se aperfeiçoa a habilidade de ouvir, discursar, negociar e respeitar. A desvalorização da docência e o prestígio da pesquisa, que geram um esvaziamento pedagógico na formaçấo do professor universitário, implicam, portanto, não apenas nos resultados da educação em cursos de graduaçáo, mas também em nossa compreensão de sociedade, percepção e intervenção no mundo em que vivemos.

\section{O produtivismo acadêmico}

Mesmo diante de algumas iniciativas na década de 1930 e da criaçáo da então Campanha de Aperfeiçoamento de Pessoal para o Ensino Superior (Capes) 
na década de 1950, é o Parecer no 977, de 03 de dezembro de 1965 (BRASIL, 1965), que reconhece a pós-graduação como um novo nível de ensino (HOSTINS, 2006). O parecer dispóe sobre a implantação de cursos de pós-graduação, visando dar uma conceituação mais precisa, de caráter operacional, ditando a natureza, a regulamentação e a funçáo dos cursos em formar os pesquisadores e docentes brasileiros de cursos superiores.

Sobre a concepção da Capes, cabe destacar que seu propósito como "Campanha" tinha relação exatamente com o combate à falta de formação dos professores que atuavam nas universidades públicas (BIANCHETTI; VALLE; PEREIRA, 2015). Somente depois de resolvida a deficiente titulação dos docentes, nas poucas instituições de ensino superior existentes no período, é que o termo foi substituído por "Coordenação". É a partir de 1990 que a Capes adota a "formação de pesquisadores". Após esse período, "a regulação passa a informar e a conformar o financiamento" (BIANCHETTI; VALLE; PEREIRA, 2015, p. 58), o que insere a competitividade nos programas e na vida profissional dos pesquisadores. $\mathrm{O}$ fomento ao desenvolvimento científico leva à profissionalização acadêmica de professores e pesquisadores, que se tornam especialistas e produtores em larga escala de conhecimentos específicos e aplicáveis (BIANCHETTI; VALLE; PEREIRA, 2015). Ao mesmo tempo, a relação entre avaliação e financiamento é uma infalível estratégia para submeter profissionais e programas de pós-graduação às regulamentaçóes impostas pela Coordenação.

Bianchetti, Valle e Pereira (2015), ao tratarem das temáticas intelectuais e da produção de conhecimento no âmbito dos programas de pós-graduação no Brasil, o fazem criticando tanto a perda da autonomia do campo científico - o controle exercido pelos órgáos de Estado e a centralidade do campo econômico pelo viés do racionalismo de mercado - quanto a passividade - a ausência e a conformidade dos acadêmicos. No Brasil, se produz e se publica cientificamente cada vez mais, porém com qualidade discutível, pois o impacto e o número de citações das publicaçóes estão abaixo da média mundial (BIANCHETTI; VALLE; PEREIRA, 2015). É comum, na esfera acadêmica, a crítica à reapresentação ou apenas readequação das mesmas produçôes científicas para dar conta das exigências de publicação, assim como à prática de autoplágio ou inserção de nomes de pesquisadores em artigos para os quais pouco ou nada contribuíram. A produção de artigos se torna uma tarefa em série, como uma linha de montagem.

Para os pesquisadores, a avaliação realizada pela Capes "delimita, enquadra e subsume" os intelectuais de modo a alijá-los de engajamento ou de uma atuação efetivamente social e política (BIANCHETTI; VALLE; PEREIRA, 2015, p. 75), assim como de produção qualificada e de veiculação democrática de conhecimento. Logo, ocorre uma reconfiguração dos intelectuais pressionados por uma visão utilitária denominada de "capitalismo acadêmico". Associado a esta perspectiva, encontra-se o conceito de sociabilidade produtiva, definido por Sguissardi e 
Silva Júnior (2009, p. 46-47) como "nova forma de ser do professor-pesquisador", diante da lógica de mercantilização da universidade (de "financiamentos, tempos e controles impostos pelo capital produtivo"), caracterizada pela intensificação do trabalho que o leva "à exaustão por vontade própria".

Macedo (2015, p. 761) diverge desse posicionamento, ainda que não negue a pressão da cultura da performatividade e a "luta por verbas e prestígio acadêmico". Em artigo no qual discorda de que haja uma corrida produtivista na área de educação, afirma que se publica pouco - muitos docentes não elaboram dois textos por ano, nem sempre com a qualidade desejada, especialmente porque a pesquisa em educação está se constituindo lentamente nos últimos 20 anos. Macedo (2015) desconsidera as más práticas como autoplágio e o "fatiamento" dos resultados em diversos artigos como hábitos disseminados, e, ainda, critica o discurso produtivista por julgá-lo desmobilizador e comprometedor do esforço pela constituição de um sistema de ciência e tecnologia. Como uma ação política efetiva para alterar esse cenário, a pesquisadora aponta uma atuação incisiva junto aos cursos de pós-graduação menos consolidados. Kuhlmann Jr. (2015), por sua vez, ressalta que não se pode atribuir ao produtivismo acadêmico, isoladamente, toda a responsabilidade pelos infortúnios da pesquisa e pelas adversidades enfrentadas pelos docentes. A pesquisa é recompensadora, traz satisfação pessoal. Há inúmeros outros problemas que afetam e precarizam o trabalho docente, assim como a disputa por espaços de poder, notoriedade e financiamento são anteriores à política produtivista. Entretanto, os trabalhos citados não abordam o impacto da cultura da performatividade no esvaziamento na prática da docência.

Bianchetti, Valle e Pereira (2015, p. 86) declaram que a produção científica predeterminada, os prazos, a quantificação e os escores implicam no "fim da categoria dos intelectuais na acepção clássica do termo". Os intelectuais são substituídos por produtivos e competentes funcionários, com uma atuação fechada em suas especialidades e disciplinas. Não há tempo para a crítica. São os intelectuais institucionalizados. "O intelectual deixa de existir quando não tem mais uma causa ou a causa que abraça/absorve não é suficientemente provocadora para que ele se engaje, indo além do cumprimento de tarefas institucionalizadas e pré-agendadas" (BIANCHETTI; VALLE; PEREIRA, 2015, p. 96). Tanto Bianchetti, Valle e Pereira (2015) quanto Chauí (2006) entendem que enquanto os pesquisadores têm problemas, os intelectuais possuem causas, e que cabe, portanto, aos intelectuais, um papel de contraposição. Por outro lado, as imposições da lógica gerencial em relação ao campo científico podem causar o silenciamento dos intelectuais ou, ainda, sua reconfiguração (em intelectuais institucionalizados atados às agências de fomento) ou desaparecimento. O produtivismo acadêmico, entáo, é apontado como fator que atrapalha tanto a formação quanto a atuação dos intelectuais em nosso país.

Bianchetti, Valle e Pereira (2015) não negam que a Capes é essencial e que há conquistas inquestionáveis na existência de um processo de avaliação. 
Tanto que exemplificam essa questáo citando desde injunçóes que regulamentaram questôes extremamente pertinentes em relação à pesquisa, como definição de duração máxima dos cursos de mestrado e doutorado ou maior rigidez no controle de desistências e abandono dos cursos, até a melhor definição dos contornos das pesquisas, o aprimoramento das orientaçóes, a realizaçáo de pesquisas interinstitucionais, a aplicação de novas tecnologias na coleta de dados e em outras etapas e as atividades da pesquisa, o relacionamento mais orgânico da pós-graduação com a graduação, entre outros fatores.

Os autores consideram que, diante do financiamento público para a ciência, com a finalidade de contribuir para o desenvolvimento científico e tecnológico, a avaliação influencia positivamente em maior transparência, responsabilidade e compromisso. Todavia, salientam que os mecanismos de avaliação adotados, com um controle cada vez mais rígido em relação ao processo de fazer científico e de trabalho do pesquisador, tornam a vida acadêmica um trabalho mecânico, afinal, para fazer ciência com qualidade - e não apenas a fim de engrossar as estatísticas oficiais —, é necessário se ter condições favoráveis de trabalho e tempo.

\section{O que diz a Capes}

A análise empreendida em relação à documentação da Capes foi exploratória a partir de textos disponíveis na página interna sobre "Legislação" em seu site. Os documentos mais pertinentes estão apresentados no Quadro 1.

\section{Quadro 1}

Levantamento dos documentos analisados em relaçáo à Capes.

\begin{tabular}{|c|c|}
\hline Documento & Descriçáo \\
\hline Decreto $\mathrm{n}^{\circ} 3.860 / 2001$ & $\begin{array}{l}\text { Dispóe sobre a organizaçáo do ensino superior, a avaliaçáo de cursos e } \\
\text { instituiçóes, e dá outras providências. Com atualizaçôes do Decreto. }\end{array}$ \\
\hline Decreto $n^{\circ} 6.755 / 2009$ & $\begin{array}{l}\text { Institui a Política Nacional de Formação de Profissionais } \\
\text { do Magistério da Educaçáo Básica, disciplina a atuaçáo da } \\
\text { Coordenação de Aperfeiçoamento de Pessoal de Nivel Superior } \\
\text { (Capes) no fomento a programas de formaçáo inicial e } \\
\text { continuada, e dá outras providências. }\end{array}$ \\
\hline Decreto $n^{\circ} 7.692 / 2012$ & $\begin{array}{l}\text { Aprova o Estatuto e o Quadro Demonstrativo dos Cargos em } \\
\text { Comissão da Coordenação de Aperfeiçoamento de Pessoal de } \\
\text { Nível Superior (Capes) e remaneja cargos em comissão. }\end{array}$ \\
\hline $\begin{array}{l}\text { Plano Nacional da } \\
\text { Pós-Graduaçáo 2011-2020 }\end{array}$ & $\begin{array}{l}\text { O Plano Nacional de Pós-Graduação (PNPG) 2011-2020 tem } \\
\text { como objetivo definir novas diretrizes, estratégias e metas para } \\
\text { dar continuidade e avançar nas propostas para política de pós- } \\
\text { graduaçáo e pesquisa no Brasil. }\end{array}$ \\
\hline
\end{tabular}

Fonte: Elaboração própria. 
O Decreto no 3.860 (BRASIL, 2001), que dispóe sobre a organização do ensino superior, e a avaliaçáo de cursos e instituiçóes, determina em seu artigo $1^{\circ}$ que a avaliação de cursos e das Instituiçóes de Ensino Superior (IES) é de responsabilidade do Inep. Em relação aos critérios, estabelece-se, entre outros, a produção científica, tecnológica e cultural e as condiçóes de trabalho e qualificação docente. As comissóes de especialistas analisam, especificamente sobre os professores, a titulação, a experiência profissional, a estrutura de carreira, a jornada e as condiçóes de trabalho. Já o artigo $18^{\circ}$ estabelece que a avaliação de programas de mestrado e doutorado, por área de conhecimento, será realizada pela Capes, de acordo com critérios e metodologias próprios. Ao mencionar o que será considerado em termo de compromisso mediante credenciamento (ou recredenciamento) de IES, destaca as formas de participação dos professores e alunos nos órgãos colegiados responsáveis pela condução dos assuntos acadêmicos.

O Decreto no 6.755/2009 institui o Plano Nacional de Formação de Professores de Educação Básica (PARFOR), atribuindo-o à Capes, o que amplia seu espectro de atuação e é bem-vindo para uma integração entre pós-graduação e educação básica. A medida preocupa, porém, no sentido de que deve ser assegurado o acréscimo orçamentário para essa nova frente. $\mathrm{O}$ documento apresenta, entre seus princípios: "a educação de qualidade, construída em bases científicas e técnicas sólidas"; "a formação dos profissionais do magistério como compromisso com um projeto social, político e ético"; "a articulação entre a teoria e a prática no processo de formação docente, fundada no domínio de conhecimentos científicos e didáticos, contemplando a indissociabilidade entre ensino, pesquisa e extensão"; "a formação continuada entendida como componente essencial da profissionalização docente, devendo integrar-se ao cotidiano da escola e considerar os diferentes saberes e a experiência docente" (BRASIL, 2009). Em seu teor, o decreto reforça o objetivo de fortalecer a educação básica e pública por meio da formação inicial e continuada dos professores, enfatizando o papel das instituiçóes públicas de ensino superior nesse processo, promovendo a valorização do docente, por meio do estímulo ao ingresso, à permanência e à progressão na carreira. No artigo $3^{\circ}$, referente aos objetivos do PARFOR, o documento destaca: "promover a atualização teórico-metodológica nos processos de formação dos profissionais do magistério, inclusive no que se refere ao uso das tecnologias de comunicação e informação nos processos educativos". Além disso, enfatiza que a formação continuada compreende as atividades formativas e os cursos de atualização como especialização, mestrado ou doutorado.

O Estatuto da Capes é anexo ao Decreto no 7.692/2012, que reafirma, no artigo $2^{\circ}$, a finalidade da fundação pública em subsidiar o Ministério da Educação na formulação de políticas e desenvolvimento de atividades de suporte à formação de profissionais de magistério para a educação básica e superior, e para o desenvolvimento científico e tecnológico do país. O estatuto, portanto, reafirma a recente ampliação da atuação da Capes e simultaneamente retoma a finalidade que justificou seu surgimento, por meio do Decreto no 29.741, de 11 de julho de 1951, de aperfeiçoamento de pessoal de nível superior. 
No âmbito da educação superior, a CAPES terá como finalidade subsidiar o Ministério da Educação na formulação de políticas para pós-graduação, coordenar o sistema de pós-graduação e avaliar os cursos desse nível, e estimular, mediante bolsas de estudo, auxílios e outros mecanismos, a formação de recursos humanos altamente qualificados para a docência de grau superior, a pesquisa e o atendimento da demanda dos setores público e privado (BRASIL, 2012, s.n.).

Cabe à Capes, tanto a definição de padróes mínimos de qualidade para regular o funcionamento dos cursos de mestrado e doutorado no país quanto a promoção de estudos e avaliaçóes que possam desenvolver e melhorar o ensino de pós-graduação e suas atividades.

\section{O plano nacional de pós-graduação}

São seis os planos nacionais de pós-graduação (PNPG) efetivados até 2016. O I PNPG (1975-1979) institucionalizava o sistema, consolidava-o como atividade regular no âmbito das universidades e assegurava estabilidade em seu financiamento (HOSTINS, 2006). O foco estava na expansão da pós-graduação de forma mais equilibrada entre áreas e regióes. O governo, sob o discurso nacionalista e articulado a líderes da comunidade científica e universitária, estimulou a pós-graduação que, "legitimada e consolidada pelo regime militar, se expandiu e deu espaço à intelectualidade crítica e atuante no horizonte cultural do país" (HOSTINS, 2006, p. 138). Simultaneamente, estabeleceram-se uma sistemática de avaliação, em 1976, e o reconhecimento formal da Capes como órgão responsável pelo PNPG. Nos planos seguintes, prioriza-se a qualidade em vez da expansão - e, com isso, a institucionalização e o aperfeiçoamento da avaliação. Segundo as análises de Hostins (2006) e Bianchetti, Valle e Pereira (2015), é possível fazer três importantes constataçóes:

1. o Estado Brasileiro foi ampliando a participação na produção científica e a formação dos docentes que atuavam nas universidades, considerando sua importância estratégica para o desenvolvimento do país;

2. após a consolidação, o foco voltou-se para a avaliação do desempenho do sistema instituído; e

3. os enfoques do PNPG passaram a ser o desenvolvimento da pesquisa na universidade e o estreitamento das relaçóes entre ciência, tecnologia e o setor produtivo, o que poderia ser um indício do encolhimento do papel do Estado e da mercantilização da universidade - que ocorreram nos planos postos em vigência a partir da década de 1990 . 
O V PNPG (2005-2010) prioriza o fortalecimento das bases científica, tecnológica e de inovação; a formação de docentes para todos os níveis de ensino (incluindo os professores da educaçẫo básica); a formação de quadros profissionais para o mercado não acadêmico, tanto público quanto privado, em novos projetos de educação a distância e cooperaçáo internacional por intermédio das universidades (HOSTINS, 2006).

Ao analisar o redimensionamento da avaliação dos programas de pós-graduação em relação à internacionalização, Hostins (2006) aponta que ocorreu uma ruptura entre a visão de avaliação adotada pela Capes entre 1976-1998 e pós-1998. Até o ano de 1998, a avaliação tinha o intuito de direcionar os esforços de implantaçáo de cursos de pós-graduação. Em seguida, a intenção passou a ser a promoção da competição entre os programas. "Para impulsionar a internacionalização é necessário induzir os Programas à competitividade, à inovação e ao empreendedorismo, tal como funciona a lógica do setor corporativo empresarial" (HOSTINS, 2006, p. 151).

Já a sexta edição do PNPG (2011-2020) foca em uma perspectiva sistêmica (BRASIL, 2010). O texto enfatiza elementos como abordagem interdisciplinar, aproximação entre áreas diversas de conhecimento, intensificação de redes entre programas de pós-graduação e grupos de pesquisa, adensamento de centros de excelência e internacionalização. Essa visão se deve a um direcionamento para uma Agenda Nacional de Pesquisa. Entre os temas considerados estratégicos e citados na introdução do documento encontra-se a "melhoria da qualidade da Educação Básica, com foco no Ensino Médio", a partir de estudos sobre formação de professores, currículo e gestão, e uma aproximação da pós-graduação com os interesses da sociedade (BRASIL, 2010, p. 21).

Apesar de reconhecer o sistema de avaliação e financiamento da Capes como uma experiência de sucesso, o plano cita que há imperfeiçóes e necessidade de ajustes, especialmente em relação à primazia do quantitativo sobre a qualidade das produçóes, ou seja, do produtivismo também fortalecido pelo pouco espaçamento entre uma avaliação e outra. $\mathrm{O}$ documento evidencia, por outro lado, quais fatores são considerados de sucesso: a avaliaçáo por pares, sua natureza meritocrática e a associação entre reconhecimento e fomento. Além disso, sugere o espaçamento das avaliaçóes, com uma periodização mais longa para os cursos de pós-graduação mais bem avaliados e a seleção das melhores publicaçóes pelos pesquisadores para que possam ser escrutinados pelos avaliadores. Por fim, o plano reafirma o entendimento de que cursos de pós-graduação formam, para diferentes necessidades, professores e pesquisadores para o sistema de ensino e pesquisa, assim como quadros técnicos especializados para o setor público e privado. 


\section{Considerações finais}

Embora os pesquisadores da Educação apontem a necessidade de formação didático-pedagógica permanente, respeitando trajetórias profissionais e a valorizaçáo do compartilhamento de experiências superando o isolamento, as diretrizes da Capes colaboram para que a universidade e, por consequência, o professor, seja reconhecida apenas em relaçáo à capacidade de produção científica. São esses os critérios que imperam nos processos de seleção e avaliação de desempenho de professores universitários, assim como na avaliação de cursos de graduação, das IES e programas de pós-graduação.

Os documentos da Capes reafirmam o compromisso com a formação do professor que atua em cursos superiores e, a partir de 2007, ampliam a sua responsabilidade em relação à formação do professor de educação básica - com açôes de aperfeiçoamento e estímulo ao ingresso na pós-graduação; em relação ao primeiro grupo, o foco está na formação para a pesquisa, sem menção aos demais saberes necessários à prática docente. A visão, portanto, é mais global e abrangente quando se trata da formação do professor para a atuação na Escola Básica.

Atualmente, pode-se dizer que não é interesse institucional e não faz parte do escopo de atuaçáo da Capes que o docente do ensino superior possa refletir e teorizar sobre sua realidade em sala de aula, construindo e reconstruindo sua prática pedagógica. Também não se valoriza o engajamento, característica legitimadora e marca da atuação social dos intelectuais, embora os itens "impacto/inserção" e "solidariedade" sejam novos parâmetros de avaliaçáo de cursos. Entende-se que a formação do pesquisador seria suficiente para formar o professor e o intelectual.

Por outro lado, as universidades, tanto públicas quanto privadas, reproduzem essa visão, pois ainda são raros os programas de formação didático-pedagógicos permanentes, desenvolvidos a partir das necessidades dos docentes, que conseguem gerar conhecimento, apaziguar inseguranças do contato ativo com os estudantes, e estimular o trabalho cooperativo de forma a socializar os saberes e as experiências - o que também contribui para o esvaziamento político e ideológico da profissão docente.

Ao tecer a crítica ao produtivismo acadêmico, enfatizando o papel dos intelectuais na sociedade, Bianchetti, Valle e Pereira (2015) ressaltam não apenas a perda da autonomia do campo científico, o controle exercido pelos órgãos de Estado e a centralidade do campo econômico pelo viés do racionalismo de mercado, mas também a passividade (ou a sociabilidade produtiva), a ausência e a conformidade dos acadêmicos que estabelecem poucas formas de resistência. Os intelectuais acadêmicos se reconfiguram em intelectuais institucionais, voltados ao cumprimento de suas tarefas e atribuiçôes, priorizando, em relação ao seu raro tempo, aquelas pelas quais são julgados, legitimados e reconhecidos. 
A conclusão é de que as políticas públicas voltadas ao acompanhamento e à avaliação dos programas de pós-graduação, embora se pronunciem planos sistêmicos, direcionados à interdisciplinaridade, ainda não consideram a multiplicidade de saberes necessários para uma boa atuação do professor universitário, como se bastasse formá-lo para a pesquisa; como se uma única disciplina ou algumas horas de estágio em docência fossem suficientes para a formação didático-pedagógica. Se couber a essa fundação pública a formação ou a regulação em relação à formação dos professores universitários, torna-se necessário rever essa lacuna.

O mesmo conceito de rede de sociabilização de conhecimento e legitimidade que perpassa os intelectuais acadêmicos na perspectiva de divulgação científica e construção de notoriedade poderia nortear o compartilhamento de conhecimentos e experiências pedagógicas dentro das universidades, rompendo com o individualismo como diretriz de programas institucionais; uma rede interna em perspectiva institucional que poderia se estender, por meio de estímulo e fomento, a redes interinstitucionais, valorizando as experiências voltadas ao ensino.

É preciso reconhecer que a atuaçáo na sala de aula da universidade é um espaço privilegiado de interlocução, sendo imprescindível o desenvolvimento profissional para um exercício de excelência. Assim, é urgente resgatar que os professores são intelectuais, na medida em que sua atuação, no front da pesquisa ou docência, implica na transformação de realidades individuais, coletivas e sociais.

\section{Notas}

1. Por meio da realização de 49 entrevistas com professores-pesquisadores de sete instituiçôes federais de ensino superior, no ano de 2007, Sguissard e Silva Júnior (2009) afirmam que a valorização dos programas de pós-graduação, a partir da década de 1960, implicou no desprestígio da graduação e da aula em si. Parte substancial das aulas cabe aos professores substitutos.

2. Para Teixeira (2010), a universidade deve estabelecer um intenso diálogo com a sociedade. Teixeira enfatiza o papel da universidade na difusão do conhecimento, no rompimento com o autodidatismo dos professores e na formação dos intelectuais.

3. Em 1932, um grupo de intelectuais lançou um documento denominado "Manifesto dos Pioneiros da Educação Nova”, que defendia uma escola única, pública, laica, obrigatória e gratuita. Entre eles, estavam Anísio Teixeira, Fernando de Azevedo e Lourenço Filho. Apesar de terem firmado um compromisso com a educação, apresentando, nesse sentido, uma posiçáo convergente, não havia uma visão uniforme e monolítica que caracterizasse o grupo. Não há a pretensão, neste texto, de discutir os sentidos políticos, consensos e dissensos desses intelectuais e, por recorte, optamos em enfatizar o diálogo com Anísio Teixeira e suas concepçóes.

4. Na pós-graduação, o trabalho não está apenas sob o domínio do professor; há uma vulnerabilidade, fruto das avaliaçóes externas. O fator psicológico define o trabalho como um "consumidor emocional" (SGUISSARD; SILVA JÚNIOR, 2009, p. 176). 


\section{Referências}

BIANCHETTI, L.; VALLE, I.R.; PEREIRA, G.R.M. O fim dos intelectuais acadêmicos? Induções da Capes e desafios às associaçóes científicas. Campinas, SP: Autores Associados, 2015.

BRASIL. Parecer no 977/1965. Definição dos cursos de pós-graduação. Disponível em: $<$ https://www.capes.gov.br/images/stories/download/legislacao/Parecer_CESU_977_1965. pdf>. Acesso em: 15 dez. 2015.

Lei $\mathrm{n}^{\circ}$ 9.394, de 20 de dezembro de 1996. Estabelece as diretrizes e bases da educação nacional. Disponível em: <http://www.planalto.gov.br/ccivil 03/leis/L9394. htm>. Acesso em: 15 dez. 2015

Decreto $\mathrm{n}^{\circ} 3.860$, de 9 de julho de 2001. Dispóe sobre a organização do ensino superior, a avaliação de cursos e instituiçóes, e dá outras providências. Disponível em: <http://www.capes.gov.br/images/stories/download/legislacao/Decreto3860_2001.pdf>. Acesso em: 15 dez. 2015.

Decreto no 6.755, de 29 de janeiro de 2009. Institui a Política Nacional de Formação de Profissionais do Magistério da Educação Básica, disciplina a atuação da Coordenação de Aperfeiçoamento de Pessoal de Nível Superior - CAPES no fomento a programas de formação inicial e continuada, e dá outras providências. Disponível em: <http:/www.planalto.gov.br/ccivil 03/ ato2007-2010/2009/decreto/d6755.htm>. Acesso em: 15 dez. 2015.

. Ministério da Educação. Coordenação de Aperfeiçoamento de Pessoal de Nível Superior. Plano Nacional de Pós-Graduação 2011 - 2020. Brasília, DF: CAPES, 2010. Disponível em: <http://www.capes.gov.br/images/stories/download/Livros-PNPG-VolumeI-Mont.pdf $>$. Acesso em: 15 dez. 2015.

- Decreto no 7.692, de 2 de março de 2012. Aprova o Estatuto e o Quadro Demonstrativo dos Cargos em Comissão da Coordenação de Aperfeiçoamento de Pessoal de Nível Superior - CAPES, e remaneja cargos em comissão. Disponível em: $\leq$ http:// www.planalto.gov.br/ccivil 03/ Ato2011-2014/2012/Decreto/D7692.htm>. Acesso em: 15 dez. 2015.

CHAUÍ, M. Intelectual engajado: uma figura em extinção? In: NOVAES, A. (Org). O silêncio dos Intelectuais. São Paulo: Companhia das Letras, 2006. p. 19-43.

CUNHA, M.I. Aprendizagem da docência em espaços institucionais: é possível fazer avançar o campo da formação de professores? Avaliação, Campinas; Sorocaba, SP, v. 19, n. 3, p. 789-802, 2014.

CUNHA, M.I.; ZANCHET, B.B.A; RIBEIRO, G.M. Qualidade do ensino de graduação: cultura, valores e seleção de professores. Práxis Educativa, v. 8, p. 219-242, 2013.

HOSTINS, R.C.L. Os Planos Nacionais de Pós-graduação (PNPG) e suas repercussões na Pós-graduação brasileira. Perspectiva, Florianópolis, v. 24, n. 1, p. 133-160, 2006.

KUHLMANN JR., M. Produtivismo acadêmico, publicação em periódicos e qualidade das pesquisas. Caderno de Pesquisa, v. 45, n. 158, p. 838-855, 2015. 
MACEDO, E. Cultura performativa e pesquisa em educação: desafios para a ação política. Caderno de Pesquisa, v. 45, n. 158, p. 752-774, 2015.

MENDONÇA, A.W. Anísio Teixeira e a universidade de Educação. Rio de Janeiro: Universidade do Estado do Rio de Janeiro, 2002.

RIBEIRO, R.J. O cientista e o intelectual. In: NOVAES, A. (Org). O silêncio dos Intelectuais. São Paulo: Companhia das Letras, 2006. p. 137-149.

SGUISSARDI, V.; SILVA JÚNIOR, J.R. Trabalho Intensificado nas federais: pós-graduação e produtivismo acadêmico. São Paulo: Xamã, 2009.

RUIZ, C.M. El desafío de los profesores principiantes universitarios ante su formación. In: MARCELO, C. (Org.). El profesorado principiante: inserción a la docencia. Barcelona: Octaedro, 2008. p. 177-210.

SIRINELLI, J.F. Os intelectuais In: RÉMOND, René. Por uma história politica. Rio de Janeiro: UFRJ/FGV, 1996. Disponível em: <http://docslide.com.br/documents/remondrene-por-uma-historia-politica.html>. Acesso em: 20 nov. 2015

. Jean Paul Sartre, um intelectual engajado. In: NOVAES, A. (Org.). O silêncio dos intelectuais. São Paulo: Companhia das Letras, 2006. p. 161-170.

SOARES, S.R.; CUNHA, M.I. Formação do professor: a docência universitária em busca de legitimidade. Salvador: EDUFBA, 2010. 134 p. Disponível em: <http://static.scielo. org/scielobooks/cb/pdf/soares-9788523211981.pdf>. Acesso em: 25 out. 2015.

TEIXEIRA, A.S. Educação e Universidade. Rio de Janeiro: UFRJ, 2010.

ZABALZA, M.A. O ensino universitário: seu cenário, seus protagonistas. Porto Alegre: Artmed, 2004.

Recebido em 05 de maio de 2016.

Aprovado em 29 de setembro de 2016. 